\title{
La judicialización de la ejecución de la pena privativa de la libertad. El fallo "Romero Cacharane" de la Corte Suprema de Justicia de la Nación
}

The judicialization of the execution of the custodial sentence. The "Romero Cacharane" ruling of the Supreme Court of Justice of the Nation

Judicialização da execução da pena de privação de liberdade. A decisão "Romero Cacharane" do Supremo Tribunal de Justiça da Nação

Judiciarisation de l'exécution de la peine privative de liberté. La décision "Romero Cacharane" de la Cour Suprême de Justice de la Nation 执行监禁刑的司法化. 执政的 “Romero Cacharane” 国 家最高法院

\begin{tabular}{l|l} 
Ignacio Fernández Camillo & $\mid \begin{array}{l}\text { Universidad Nacional } \\
\text { de La Plata }\end{array}$
\end{tabular}

Revista Derechos en Acción ISSN 2525-1678/ e-ISSN 2525-1686

Año 4/No 12 Invierno 2019 (21 junio a 20 septiembre), 459-467

DOI: https://doi.org/10.24215/25251678e313

ORCID: https://orcid.org/0000-0003-3878-1255

Recibido: 7/05/2019

Aprobado: 16/06/2019

Resumen: En base a un somero análisis del fallo de la CSJN "Romero Cacharane", el artículo busca desentrañar la judicialización de la ejecución de la pena privativa de libertad a partir de la ley nacional 24.660. Se

\footnotetext{
Abogado egresado de la Facultad de Ciencias Jurídicas y Sociales de la Universidad Nacional de La Plata..
} 
trata de un análisis que se conforma una investigación más amplia sobre las potestades que el Servicio Penitenciario posee en la ejecución de la pena privativa de libertad, convirtiéndose por momentos en "soberano" en la punición del/a detenido/a.

Palabras claves: Judicialización-ejecución de la pena

Abstract: Based on a brief analysis of the ruling of the Supreme Court of Justice "Romero Cacharane", the article seeks to unravel the judicialization of the execution of the custodial sentence based on national law 24.660. This is an analysis that constitutes a broader investigation into the powers that the Penitentiary Service has in the execution of the sentence of deprivation of liberty, becoming at times "sovereign" in the punishment of the detainee.

Keywords: Judicialization-execution of the sentence.

Resumo: Com base em uma breve análise da decisão do STJN “Romero Cacharane", o artigo procura desvendar judicialização da execução da pena de privação de liberdade a partir da lei nacional 24.660. É uma análise que se ajusta a uma investigação mais ampla sobre os poderes que o Serviço Penitenciário tem na execução da pena privativa de liberdade, tornando-se às vezes em "soberano" na punição do/da detento/a.

Palavras-chave: Judicialização-execução da pena de privação de liberdade.

Résumé: Basée sur une analyse sommaire de la décision du CSJN "Romero Cacharane", cet article cherche à comprendre la judiciarisation de l'exécution de la peine de privation de liberté à partir de la loi nationale 24.660. Cette analyse s'inscrit dans le cadre d'une investigation plus large sur les pouvoirs dont dispose le Service pénitencier dans l'exécution de la peine privative de liberté, devenant par moment "souveraine" quand à la punition du/de la détenu/e.

Mot-clés: Judiciarisation-exécution de la peine

摘要: 根据对CSJN “Romero Cacharane” 裁决的简要分析, 该条旨 在解释对剥夺自由刑的执行从国家法律24,660的起诉. 这是一项分 析, 符合对监狱服务部执行监禁刑的权力进行更广泛的调查, 有时在 惩罚被拘留者方面成为“主权”.

关键字: 关键字:司法化, 执行判决 


\section{Introducción}

Una de las finalidades del Servicio Penitenciario es la administración del cumplimiento de la función de la pena privativa de libertad. Esta tarea es asignada y reglamentada a nivel nacional por la ley 24.660.

El hecho de privar a una persona de su libertad acarrea la adopción de un conjunto de determinaciones que adquieren una relevancia superlativa en la vida de quien pasa a ser "objeto" de las mismas, enmarcadas éstas en un concepto de prisionización. Así, cada vez que mediante una resolución administrativa interna se dispone cualquier medida referente a la forma de prisionización de un detenido dentro de la unidad carcelaria, se está redefiniendo la situación mediante la cual una persona privada de la libertad debe adaptarse a vivir en ella ${ }^{2}$.

En nuestro sistema el conjunto de esas decisiones históricamente se encontró en manos del Servicio Penitenciario y lo cierto es que esta reconfiguración del mundo del/a detenido/a fundada sólo en la decisión "discrecional" de una sola agencia penal sin siquiera la revisión del Juzgado o Tribunal a cargo del detenido, termina por configurar una práctica arbitraria.

El fallo "Romero Cacharane" viene a tratar de socavar esta estructura en la que el Servicio Penitenciario "administra" la función de la pena privativa de libertad y el poder judicial sólo conciente lo realizado administrativamente. Estableciendo parámetros respecto de la "judialización de la ejecución de la pena privativa de libertad".

\section{Caso "Romero Cacharane"}

Hechos: Mientras Hugo Alberto Romero Cacharane se encontraba cumpliendo su pena en una cárcel mendocina, fue

2 Es realmente complicado, sino imposible "aprender a vivir en sociedad aislado de la misma". Este absurdo, determina que luego las agencias penales deban expresarse de forma contradictoria y deshumanizadamente en la mayoría de los conflictos capilares que se suscitan en el marco de la administración de la pena privativa de la libertad. 
sancionado por el servicio penitenciario a cumplir quince días de aislamiento en el pabellón de máxima seguridad. La defensa oficial de Cacharane apeló esa sanción ante el juez de ejecución penal alegando que se había violado la garantía de defensa en juicio porque fue impuesta en ausencia de un proceso en el que pudiera defenderse del cargo por el que fuera castigado.

El juez integrante del Tribunal Oral en lo Criminal Federal $\mathrm{n}^{\circ} 2$ de Mendoza, en ejercicio de las funciones de juez de ejecución, no hizo lugar al recurso de apelación y nulidad interpuesto en esa instancia y confirmó la sanción impuesta por resolución penitenciaria $n^{\circ} 406 / 97$, por la cual se aplicaron a Romero Cacharane quince días ininterrumpidos en celda de aislamiento del pabellón de máxima seguridad de la penitenciaria mendocina, controvirtiendo lo establecido por la ley nacional de ejecución penal -ley 24.660-. El juez de ejecución consideró que, dado que dicha ley autoriza un plazo de un año para que las provincias adecuen sus normas penitenciarias, "no es obligación de la autoridad penitenciaria seguir los procedimientos que el señor Defensor Oficial pretende, máxime cuando de la sustanciación de las actuaciones que aplicaron la sanción y del tipo de la misma, no surgen elementos que indiquen un castigo injusto o ilegal o que se ha torcido la realidad para afectar al interno Romero Cacharane".

La defensa de Cacharane recurrió esa decisión ante la Cámara Nacional de Casación Penal. La Sala II de la Cámara Nacional de Casación Penal declaró mal concedido el recurso de casación interpuesto por la defensa de Hugo Alberto Romero Cacharane. Al denegar el mencionado recurso, la Sala sostuvo que es su criterio que las resoluciones que no se encuentran vinculadas con el título ejecutivo de la condena sino con la forma de cumplimiento de la pena impuesta, es decir, relacionadas con normas o reglamentos del derecho penitenciario, no son susceptibles del embate casatorio. Señaló, asimismo, que las cuestiones relacionadas con la función de control penitenciario, de competencia originariamente administrativa sólo resultan recurribles, "en algunos casos" ante el juez de ejecución, cuyas 
decisiones, a su vez, sólo "en ciertos supuestos", pueden ser objeto del recurso de apelación del artículo 18 de la ley 24.050.

El fallo de la casación fue impugnado mediante el recurso extraordinario, cuyo rechazo fue en queja a la Corte Suprema de Justicia de la Nación, bajo el argumento de que la sentencia de la Sala II de la Cámara Nacional de Casación Penal era arbitraria, en tanto dicho órgano no asumió la intervención que le asigna la normativa vigente, violando con ello el derecho constitucional a la protección judicial y a la doble instancia que entendió aplicable a la etapa de ejecución de la pena.

Fallo: El 9 de marzo de 2004 la Corte Suprema hizo lugar al planteo formulado por la defensa de Romero Cacharane (Voto de los jueces Zaffaroni, Maqueda, Petracchi, Fayt, Boggiano y Vázquez).

Según el Máximo Tribunal, las decisiones del Servicio Penitenciario que afectan la modalidad de la ejecución de una pena están sometidas al control del juez de ejecución y de la Cámara Nacional de Casación Penal -y eventualmente, de la propia Corte-. El fundamento es que los reclusos tienen el derecho constitucional a exigir que los jueces controlen toda la etapa de ejecución de la pena y, a apelar las decisiones que implican una alteración en su modo de ejecución. Este derecho a la protección judicial es necesario para asegurar que se respeten durante la detención todos los demás derechos fundamentales.

De este modo, la Corte resolvió que el derecho a la revisión judicial no comprende solamente la condena sino también todas aquellas resoluciones que sean importantes, aún durante el transcurso de la misma. Desechando la distinción que pretendió establecer la Sala de la Cámara de Casación diferenciando los planteos que hacen al "título ejecutivo de la condena" y los atinentes a la "forma de cumplimiento de la condena", dejando a estos últimos fuera del recurso de casación; lo cual desnaturaliza la evidente intención de la ley 24.660 de "judicializar" la ejecución de las penas privativas de libertad, al someterla, en todas sus modalidades, al permanente control judicial (artículo 3, ley citada). 
La Corte considera que una alteración en el modo ejecución de la pena -como es el cumplimiento de parte de la condena en una celda de aislamiento- constituye una modificación cuantitativa y cualitativa de la pena que se le impuso al condenado que justifica la revisión judicial para controlar su legalidad y proporcionalidad ${ }^{3}$.

De esta manera, busca evitarse que la pena impuesta al condenado en un proceso rodeado de todas las garantías, pueda ser alterada por decisión de las autoridades del Servicio Penitenciario $^{4}$. La Corte sostiene que esto es inadmisible porque el derecho de defensa en juicio -de la que se deriva el derecho a la revisión judicial- asiste al condenado hasta que se agote su pena.

3 “El aislamiento ininterrumpido durante 15 días [...] se trata del castigo de mayor gravedad del sistema sancionador penitenciario e implica -a diferencia de otros- no sólo un claro empeoramiento en las condiciones de ejecución de la condena, afectando todo el sistema de derechos del interno (alteración cualitativa de la pena), sino que repercute necesariamente en el régimen de progresividad penitenciario (alteración cuantitativa de la pena). Ello así, en cuanto su aplicación incide en las calificaciones de conducta y de concepto del interno, lo que a su vez y según el caso, influye en la incorporación al régimen de semilibertad, la concesión de las salidas transitorias, en el otorgamiento de la libertad condicional y en el régimen de libertad asistida [...] De lo expuesto cabe concluir que el carácter especial de la sanción de aislamiento como privación de la libertad dentro de una situación de privación de la libertad preexistente implica una modificación en las condiciones de detención de tal entidad que requiere sin lugar a dudas que su aplicación se enmarque en un proceso celosamente respetuoso de los principios del derecho penal con jerarquía constitucional" (cf. considerando $8^{\circ}$ del voto de Fayt).

4 "Es posible sostener, incluso, que el objeto mismo de las decisiones de los jueces de ejecución hace que éstos tengan carácter administrativo (cf. Luigi, Ferrajoli, 'Derecho y razón. Teoría del galantismo pena’, ed. Trotta, Madrid, 1995, pág. 408). Pero el carácter 'administrativo' no significa -como parece entenderlo la cámara-, ni mucho menos, que se trate de una categoría 'menor', que no merece ser casada". El hecho de que muchas de las disposiciones de la ley 24.660 puedan ser calificadas de "administrativas" no constituye, sin más, un argumento para excluirlas del ámbito de control del recurso casatorio, en la medida en que se encuentran afectados los derechos de los condenados amparados no sólo por la ley 24.660 -que complementa las disposiciones del Código Penal- sino también por la Constitución Nacional [...] a través de la creación de categorías vacías, el a quo ha prescindido de las normas legales aplicables al caso y ha producido un cercenamiento indebido del derecho de la recurrente a producir la revisión de la decisión que la perjudicaba, lo cual descalifica el fallo de la cámara como acto jurisdiccional válido conforme la doctrina sobre arbitrariedad de sentencias" (cf. considerandos $9^{\circ}$ y $11^{\circ}$ del voto de Petracchi). 


\section{Análisis}

El caso, tal cual llega a la Corte Suprema, en definitiva no hace más que develar esa matriz punitivista victimizante de quien resultó ser victimario, y lo hace valiéndose de un mecanismo histórico de cosificación del/a "otro/a".

Este no es ni más ni menos que el mecanismo que crea "buenos/as" y "malos/as" 5 , cuando creando ángeles y demonios sólo se terminó por destruir a las personas, reduciendo su esencia a un mecanismo perverso de determinación de las mismas. Siendo que de este modo, lo que debiera ser una decisión humana, termina siendo un mero control administrativo -tal cual el estado de policía moderado- ${ }^{6}$.

La administrativización de decisiones que debieran ser judicializadas fundamentadas y razonadas-, no es ni más ni menos que la cosificación de las personas sobre las que recae, siendo la discrecionalidad que habilitó la justicia mendocina en el caso de análisis, desde los fallos del Juez de Ejecución Penal de Mendoza y de los jueces de la Sala II de la Cámara Nacional de Casación Penal, una forma de ejercicio de poder punitivo sobre el ya ejercido a los prisionizados, en su condición de tales.

El fallo en análisis viene a intentar romper con esto, a dar validez a la ley 24.660 , la cual busca promover las decisiones

\footnotetext{
5 Jean-Paul Sartre nos dice en "Reflexiones sobre la cuestión judía" que nosotros hemos creado esa especie de hombres que no tiene sentido sino como producto artificial de una sociedad capitalista (o feudal), que no tiene otra razón de ser que servir de chivo expiatorio a una colectividad aún prelógica (Ed. Debols!llo, Buenos Aires 2004, p. 127). Esta idea de cosificación de las personas se ve reutilizada y adaptada a nuestra actualidad por Eugenio Raúl Zaffaroni quien en "El enemigo en el derecho penal" marca que la esencia del trato diferencial que se depara al enemigo consiste en que el derecho le niega su condición de persona y sólo lo considera bajo el aspecto de ente peligroso o dañino (Ed. Ediar, Buenos Aires 2007, p. 18). La concepción cosificadora de las personas aún nos trasciende, y logra una atemporalidad que sólo nos compromete como sociedad.

6 Así lo determinan las resoluciones del Juez de Ejecución Penal de Mendoza y de la Sala II de la Cámara de Casación Penal que intervienen en el caso de autos (v. considerandos $2^{\circ}$ y $4^{\circ}$ del Fallo de la C.S.J.N., en donde se hace mención a las instancias previas del caso y como se redujo a decisión administrativa lo que en realidad debió ser judicializado en busca de una decisión humana).
} 
fundamentadas y razonadas respecto de las diferentes circunstancias que repercuten en la esfera de la persona que se encuentra privada de su libertad.

Es en prócura de esto que la CSJN determina un camino que exige la "judicialización" de la ejecución de la pena privativa de libertad, reafirmando las finalidades de la ley de ejecución penal (ley 24.660), y en la búsqueda de "humanizar" decisiones que desde la sesgada visión punitivista no debieran ser más que meramente administrativas y libradas a la discrecionalidad del Servicio Penitenciario como soberano ${ }^{7}$ en la ejecución de las penas privativas de libertad, en una especie de autoridad concentracionaria de toda la pulsión punitiva contenida en la sociedad.

\section{Conclusión}

El castigo se trasluce como un aparato que busca hacer frente a lxs "delincuentes", una entidad administrativa circunscrita, discreta y legal; siendo también la expresión del poder del Estado, la afirmación de la moralidad colectiva, un vehículo de la expresión emocional, una política social condicionada por motivos económicos, la representación de la sensibilidad vigente y un conjunto de símbolos que despliega un ethos cultural y ayuda a crear una identidad social. En tanto elemento de la organización social, aspecto de las relaciones sociales e ingrediente de la psicología individual, la penalidad es un hilo conductor que recorre todas las capas de la estructura social, vinculando lo general con lo particular; el centro con los límite. Lo que superficialmente es un medio para manejar a los trasgresores de manera que los demás podamos vivir "tranquilos" es en realidad una institución social que ayuda a definir la naturaleza de nuestra sociedad, el tipo de relaciones que la componen y la clase de vida posible y deseable. ${ }^{8}$

7 Cf. Thomas Hobbes, "Leviatán. O la materia, forma y poder de una república eclesiástica y civil", Ed. Fondo de Cultura Económica, Séptima Reimpresión, Buenos Aires 2009, Capítulo 18, "De los Derechos de los Soberanos por Institución".

8 Cf. David Garland, "Castigo y sociedad moderna. Un estudio de teoría social.", Editorial Siglo XXI, traducción de Berta Ruiz de la Concha, segunda reimpresión, 2010, página 333. 
Así, el actuar en el caso de análisis de los diferentes agentes "punitivos" es una sobrada demostración de cómo, más allá de lo resuelto por la Corte Suprema, aflora en nuestros agentes punitivos el resurgimiento de las sanciones punitivas de la $<$ justicia expresiva $>$, con esto se quiere decir que el castigo transmite el sentimiento del público, y se ha formado un nuevo consenso rígido en torno de medidas penales que se perciben como duras y agradables por parte del público, con clichés del estilo de: $<$ la verdad en la condena $>$, $<$ prisiones sin lujos $>$, $<$ condenas adultas para delitos adultos $\rangle$, $<$ tolerancia cero $\rangle$, $<$ duro con el delito, duro con las causas del delito $>^{9}$, que con el reduccionismo irreductible de los clichés no hacen más que desmembrar un tejido social por demás frágil, poniendo en jaque continuamente la dignidad de las personas en su conjunto.

\section{Referencias}

1. Foucault, Michel (1992). Microfísica del poder. Madrid, Ed. de La Piqueta.

2. Foucault, Michel (2008). Vigilar y castigar. Nacimiento de la prisión. Argentina, Ed. Siglo XXI.

3. Garland, David (2005). La cultura del control. Crimen y orden social en la sociedad contemporánea. Barcelona, Editorial Gedisa.

4. Garland, David (2010). Castigo y sociedad moderna. Un estudio de teoría social. Editorial Siglo XXI.

5. Hobbes, Thomas (2009). Leviatán. O la materia, forma y poder de una república eclesiástica y civil. Ed. Fondo de Cultura Económica.

6. Sastre, Jean-Paul (2004). Reflexiones sobre la cuestión judía. Ed. Debolsillo.

9 Cf. David Garland, "La cultura del control. Crimen y orden social en la sociedad contemporánea", Editorial Gedisa, traducción de Máximo Sozzo, primera edición, Barcelona, abril de 2005, Capítulo I. "Una historia del presente". Corrientes de cambio. 